\title{
A STUDY ON STARTER CULTURES USED \\ IN BUFFALO CURD PRODUCTION BASED \\ ON MARKET SAMPLES
}

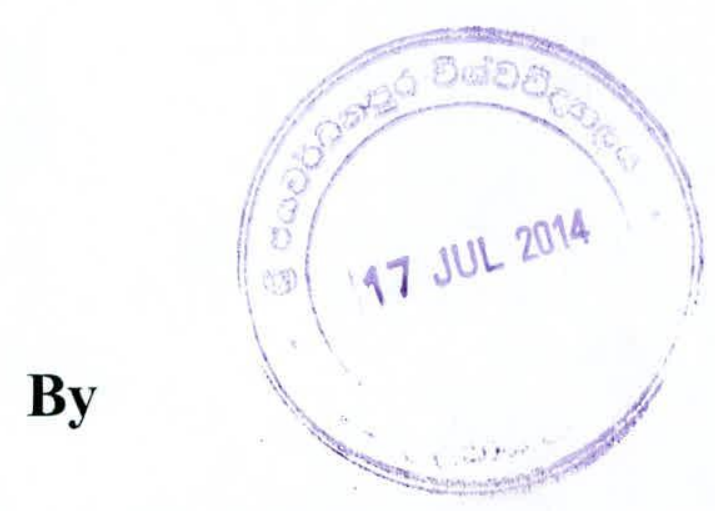

\section{DILARI YURESHA HENDAWITHARANA}

This Thesis submitted in partial fulfillment of the requirements

for the Degree of Masters of Food Science and Technology,

Department of Food Science and Technology,

Faculty of Applied Science,

University of Sri Jayewardenepura,

Sri Lanka 


\section{DECLARATION}

"This work described in this thesis was carried out by me under the guidance of Professor (Mrs.) S. C. Wijeyaratne and a report on this has not been submitted in whole or in part to any University or any other institution for another Degree/ Diploma"

$10.03 \cdot 2014$

\section{Date}

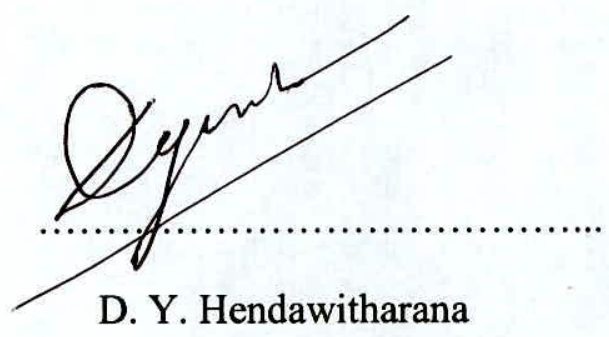


This is to certify that this report is based on the study carried out by the candidate herself and is now approved for submission.

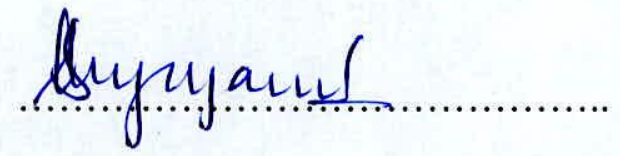

Signature

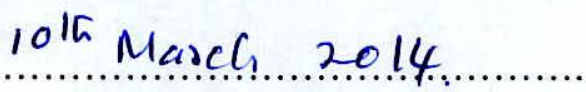

Date

Supervisor

Prof. (Mrs.) S.C. Wijeyaratne,

Senior Professor of Botany,

Department of Botany,

Faculty of Applied Sciences,

University of Sri Jayewardenepura,

Nugegoda,

Sri Lanka. 


\section{ACKNOWLEDGEMENT}

It is never an easy task to acknowledge comprehensively all the assistance received in a wide spectrum of activities carried out during a research project. However, with my apology and gratitude to those who have been inadvertently omitted in this acknowledgement, the failure to place on record the following would certainly make this research less value.

Therefore, firstly I must gratefully acknowledge my intellectual indebtedness to the panel of lecturers at the Department of Food Science for their dedicated teaching and imparting knowledge in the field of Food Science and Technology during this academic course.

I also must specially offer my profound gratitude to my supervisor, Prof. (Mrs.) S. C. Wijeyaratne, Senior Professor of Botany, Department of Botany, University of Sri Jayewardenapura for her brilliance guidance, expertise and supervision, throughout this research and almost during a period of one year.

I also wish to acknowledge Ms. Priyadarshanee of Dept. of Microbiology, University of Kelaniya, and Dr. P.S. (Mrs) Fernado, and other staff members of Veterinary Research Institute of Gannoruwa for providing me necessary research materials for this research.

I would like to thank the academic and non academic staff of the Department of Botany and Department of Food Science, University of Sri Jayewardenapura, though unnamed here, who extended their assistance to me in numerous ways during this research.

Finally, I would be failing, had I omitted to place on record, my deep appreciation to my nuclear family members for their patience to less attendance my family obligations specially during the terminal phase of this work. 


\title{
CONTENTS
}

\author{
PAGE \\ LIST OF TABLES \\ LIST OF FIGURES \\ VI \\ ABSTRACT \\ VII
}

\section{CHAPTER 1}

1. INTRODUCTION 01

$1.1 \quad$ General Introduction

01

1.2 The Objectives of the Study

03

CHAPTER 2

2. LITERATURE REVIEW

$\begin{array}{lll}2.1 & \text { Backdrop } & 04\end{array}$

$\begin{array}{lll}2.2 & \text { Importance of Curd }\end{array}$

$\begin{array}{ll}\text { 2.2.1 Nutritional and Therapeutic Value } & 07\end{array}$ 
2.4 Use of starter Cultures in the Production of curd

2.8.2 Morphological and Biochemical Characteristics

2.8.3 Differential Identification of Cocci Group of Lactic

Acid Bacteria

2.8.4 Differentiation of Lactic Acid Forming Cocci from

Members of the Cocci Group

2.8.5 Differentiation of Genus Streptococci

2.8.6 Genus Lactobacilli 
2.9.1 Culture Media Used for Growth

of Lactic Acid Bacteria

\section{CHAPTER 3}

\section{MATERIALS AND METHODOLOGY}

3.1 Sampling

3.1.1 Selection of Curd Product

3.1.2 Identification of Type of Culture Used

3. 1.3 Selection of Starter Cultures

3.2 Isolation Methods

3.3 Identification of Isolated Bacterial

Colonies

3.3.1 Preparation of Pure Cultures

3.3.2 Identification of Pure Bacterial Isolates

3.4 Differential Identification of the Lactic

Acid Bacteria

3.4.1 Identification of Different Genera of

Cocci

3.4.1.1 Identification of Lactococci 43

3.4.2 Identification of Lactobacilli 46

3.4.3 Identification of Leuconostoc spp. 


\section{CHAPTER 4}

4. RESULTS AND DISCUSSION 48

4.1 Selection of Samples 48

4.2 Identification of Type of Starter Cultures 49

4.3 Identification of Colony Characteristics 51

4.3.1 Primary Inoculation $\quad 51$

4.4 Identification of Isolated Bacterial Colonies 52

4.5 Microscopic Appearance of Presumptive

Pure Cultures of Bacterial Colonies

4.6 Identification of Lactic Acid Bacteria 55

4.7 Differential Identification of the Lactic

$\begin{array}{ll}\text { Acid Bacteria } & 58\end{array}$

$\begin{array}{lll}4.8 & \text { Discussion } & 64\end{array}$

\section{CHAPTER 5}

5. CONCLUSION AND RECOMMENDATIONS 69

$\begin{array}{ll}\text { REFERENCES } & 71\end{array}$

$\begin{array}{ll}\text { APPENDICES } & 76\end{array}$ 


\section{LIST OF TABLES}

\section{PAGE}

Table 2.1 Milk Production and Manufacture of

Milk Products in SL

Table 2.2 Consumption of milk/milk Products in

South Asian Countries

Table 2:3 Milk Composition Analysis

Table 2:4 Summary of starter Cultures and Cultured Milk

Table 2:5 Classifications of Lactic Acid Bacteria

Table 2.6 Differentiation of Genus Streptococcus Based on Physiological Tests

Table 3:1 Presumptive bacteriological identification

Table 4.1 Selection of Curd Samples based on Consumer Preferences

Table 4.2 Sample Distribution in Relation to Type and

Geographical Origin

Table 4.3 Distribution of Type and Geographical

Origin of the Tested Samples

Table 4.4 Bacterial Presentation of the Tested Curd Samples 


\section{LIST OF FIGURES}

\section{PAGE}

Figure 2.1 Buffalo Population Distribution In Sri Lanka 04

$\begin{array}{lll}\text { Figure 2.2 Production of Curd } & 16\end{array}$

Figure 2.3 Glycolytic Pathway of Homofermentative

Lactic Acid Bacteria

Figure 2.4 Metabolic Pathway of Heterofermentative Lactic

Acid Bacteria

Figure 2.5 Production of Flavouring Compounds by Lactic

Acid Bacteria

Figure 4.1 Lactobacilli

Figure 4.2 Lactococci

Figure 4.3 Observation of Color Change under Hugh and Leifsons 


\begin{abstract}
Differences in market choice of curd did not solely dependent upon the organoleptic properties of the products available in the market. The consumer relied upon the quality of the product in combination with other beliefs such as the geographical origin of the product. Therefore, this research was aimed at ascertaining that whether the nature of the starter culture used and their microbial presence did have a correlation with the differences of the consumer preference. Accordingly, as far as the nature of the starter culture used in the production of curd based on the market samples available in the Western Province, it was revealed in this research that the pattern of the type of cultures used in the production of curd did not show a marked variance and significant impact on the differences of the consumer preference. For the determination of the microbial presence in relation to the variance of consumer preference, freshly made curd available in Western province selected from three different geographical origins comprising of both types of starter cultures were microscopically and biochemically tested. Accordingly, all 6 samples tested irrespective of their type of culture and geographical origin showed almost a less significant variance in microbial picture with the presence of Lactococcus lactis, Streptococcus thermophilus and Lactobacillus spp. However, two samples consisting of indigenous starter cultures from Southern and North Central Province showed a slight deviation from being devoid of Leuconostocs from the rest. Therefore, the prevalence of indiscriminative presence of lactic acid forming microorganisms in majority of tested samples with no discernible specificity to type of starter culture or geographical origin of the product indicates that the difference in consumer preference to curd was not essentially correlated with the variance of lactic acid forming microbial presence.
\end{abstract}




\section{CHAPTER 1}

\section{INTRODUCTION}

\subsection{General Introduction}

The practice of usage of 'starter cultures' in the production of curd and other fermented dairy products dates back to a longer history, even prior to the human knowledge in relating to the presence of bacteria was existent (Andreed et al, 2000). Although the attributes of the methodology of the conversion of liquid milk into a higher quality curd product were not adequately known in the past, the skill and experience gained through the traditional practices have made the industry of curd production lucrative and demanding to date. (FAO Corporate Documentary Repository). Accordingly, fairly unchanged pattern of production process coming down from past has made the production of curd is yet to remain as predominantly a traditional industry among rural folk with unskilled labour and less technological advances. Nevertheless, it is also seen from recent past that the penetration of the curd market by means of industrialized curd productions in competition to the traditional industry (Sunday Observer, 2011).

In spite of the fact that the industry of production of curd is traditional or industrialized, the production process of 'Curd' needs less manufacturing techniques. The basic form of preparation of curd includes the inoculation of heated milk with starter cultures obtained either from previously made curd or commercially available cultures. These starter cultures are rich in lactic acid forming bacteria that help to coagulate the milk proteins in heated milk (Masud et al). As a result of bio- chemical reactions of those microbes, fluid milk is converted in to semi-solid substance named curd.

The increased consumer preference to 'curd' as a highly palatable food product is largely dependent upon its natural composition and least manufacturing techniques employed in the production process (International 
Market Bureau , 2009). Accordingly, preservation of the natural qualities of the original raw material (milk) and the comparatively lower shelf - price have been able to attract an increased demand and popularity to curd more than much of the 'desert table foods' that are readily available in the market. Furthermore, as far as the consumer preferred physical properties such as specific flavor, texture, consistency and nutritional value of curd are concerned, it is the type of the 'starter culture' that plays a vital role in the determination of the aforesaid characteristics (Ahmed et al, 2004).

Despite the fact that micro- biological properties of starter cultures determine the quality of curd, the presence of wider organoleptic properties and variable shelf-life of the products available in the market indicate that the producers have less regard over the importance of the type of microbial presentation in the starter cultures used in the curd production. Furthermore, it is unlikely that traditional type of curd producers which still form a substantial part of curd production in the country, have adequate knowledge over the importance of the use of good quality 'starter cultures' for higher keeping quality and better consumer preference of curd (Wijewardana et al, 2000). On the other hand the type of starter cultures traditionally used by curd producers may have a combination of different lactic acid forming bacteria with no knowledge of their physio-chemical properties which may have negatively affected their market potential. However, the usage of commercially available starter cultures in the production of curd seems to be gradually displacing the indigenous starter cultures mainly used in traditional productions. Furthermore, when considered the newer trend of making deviations of the quality of some of the curd products from traditional form of tastes to different flavor changes, it may also be possible that certain producers may use starter cultures consisting with microbes that are used in other dairy products such as cheese and yoghurt etc (Fernando, 2000). 
In the circumstances that consumer preferences to the different curd products available in the market are highly variable and dependent upon the factors such as organolpetic properties and traditional consumer beliefs, it may be of practical importance to identify the nature of the starter cultures used in the curd production whether traditional or commercially available and their microbial pictures in order to determine that whether the variance of the type and the microbial presence do have a significant effect on the market choice. Accordingly, in the circumstances that available researches in relation to the objective of this study area are scares, this academic research attempts to fill in the gap.

\subsection{The Objectives of the Study}

To identify the nature of 'Starter Cultures' (whether indigenous or commercially available ) used in the production of curd.

To identify the microbial picture of 'Starter Cultures' in different brands of curd available in the market. 


\section{CHAPTER 2}

\section{LITERATURE REVIEW}

\subsection{Backdrop}

Buffalo curd, is a popular dessert food consumed predominantly in South Asian countries including Sri Lanka. Curd, being natural in its composition due to least manufacturing techniques involved in the production has attracted a higher consumer demand in the market. Furthermore, due to specific pattern of buffalo farming industry associated with climatic conditions in Sri Lanka, production pattern of curd also has been largely geographically related.

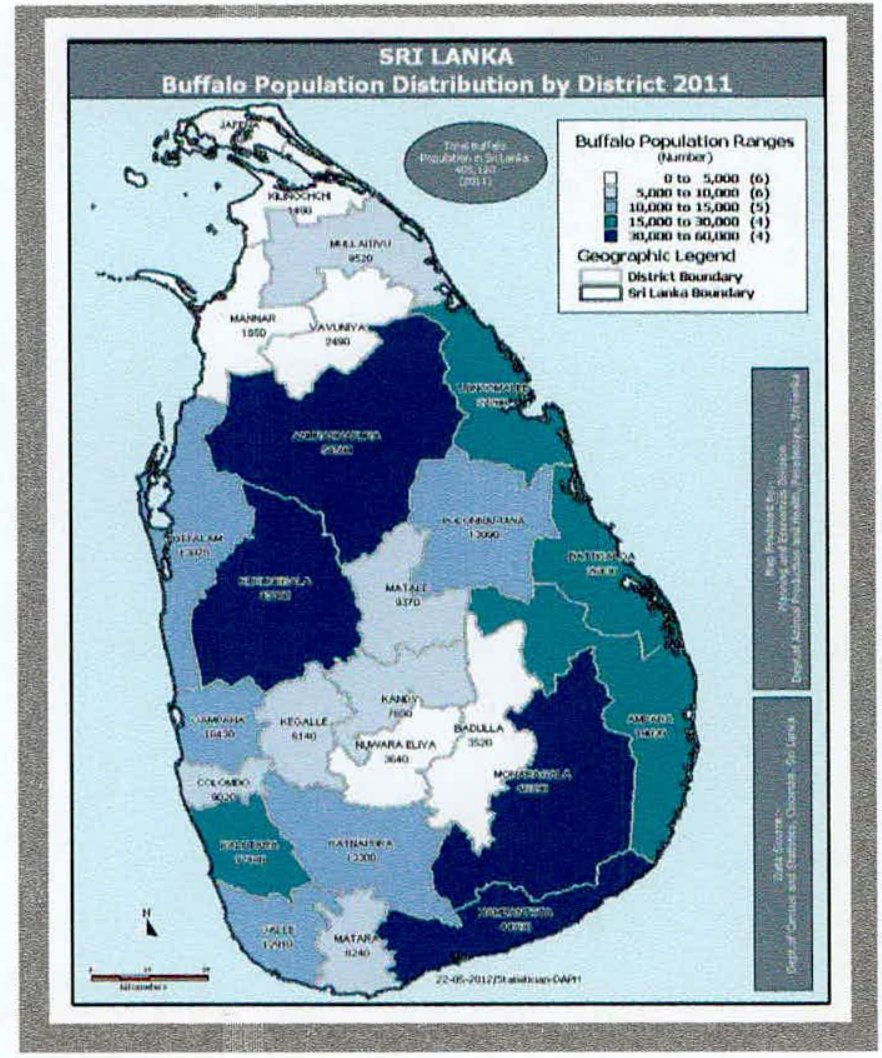

Figure : 2.1 Buffalo Population Distribution in Sri Lanka

Source: Department of Animal Production \& Health 